\title{
Objetualismo en Juan Luis Martínez: el significante palpable
}

\author{
Objectualism of Juan Luis Martínez: the palpable significant
}

\section{Zenaida Suárez M.}

Universidad de Las Palmas de Gran Canaria, Facultad de Filología, Departamento de Filología Española, Clásica y Árabe, Las Palmas, España. Correo electrónico: zenaidasuarez@gmail.com

Este trabajo explora una parte de las obras de Juan Luis Martínez, La Nueva Novela y La Poesía Chilena, referida a la inclusión de objetos en el entramado textual y que da nacimiento, dentro de la neovanguardia literaria chilena, a una nueva técnica, el objetualismo, que junto con la pictografía y el collage van a ser características de este movimiento. Este objetualismo responde a un nuevo modo de entender el texto como un entramado en el que la exclusividad de la palabra ha sido desplazada por un signo corpóreo de significante palpable, el objeto, que aumenta las posibilidades expresivas e interpretativas del signo literario y da lugar a lo que conocemos como obra-objeto.

Palabras clave: objetualismo, obra-objeto, neovanguardia, Juan Luis Martínez, literatura chilena.

In the context of the neo-avant-garde literary, this paper explores parts of two works of Juan Luis Martinez, La Nueva Novela and La Poesía Chilena, where the author incorporates objects in the textual fabric, giving birth to a new technique, the objectualism. This technique, together with the pictograph and collage became characteristics of this movement in chilean literary. The objectualism represents a new way of understanding the text, in whose body the words has been displaced by a corporeal sign with tangible significant. The object in the textual fabric enhances the expressive and interpretive possibilities of the literary signs, which results in what today we know as object-work.

Key words: objectualism, object-work, neo-avant-garde, Juan Luis Martínez, chilean literary.

\section{A MODO DE INTRODUCCIÓN}

Desde fines del siglo XIX Occidente ha sido testigo de cómo el canon literario sufrió un cambio radical en el modo de entender el modelo representacional imperante. Esta nueva filosofía anti-representacionalista favorece una serie de experimentaciones formales, categoriales y estructurales que dan como resultado unos dispositivos artísticos heterogéneos marcados por la mixtura y el deseo rupturista. La literatura ha pasado a abarcar terrenos tan aparentemente fuera de sus 
confines como la sociología, la política, la historia o la etnografía; se ha hecho eco no solo de otras temáticas, sino también de otras estrategias y de otras teorías y ha sucumbido a la radicalización del lenguaje a través del uso de elementos inusitados hasta el momento. En el caso de la poesía hispanoamericana, estas transformaciones generan una serie de artefactos que revelan procesos inestables e indeterminados de producción basados en la modificación de los mecanismos de creación de textos, en la asimilación de elementos conformadores de la escritura distintos del lenguaje verbal y en las estrategias o problemáticas de factura más ideológica que textual basadas en disciplinas no literarias. Estos procesos indeterminados, heterogéneos y aglutinadores se conocen como "mutación disciplinaria", "hibridismo cultural" (Carrasco 2002) y "asimilación interdisciplinaria" (Galindo 2004) y surgen a partir del planteamiento de la contemporaneidad literaria y artística como un tiempo de crisis en el que los discursos estables claudican ante el fragmentarismo y la experimentación.

En Chile, el impacto de este nuevo modus operandi en la literatura no es menor. Un repaso a proyectos como el creacionismo huidobriano, el surrealismo de los mandragóricos, el antipoema de Parra y los variados postulados postvanguardistas, donde las vertientes neobarroca y neovanguardista representan las corrientes más experimentales y renovadoras del panorama literario de los años más cercanos al régimen dictatorial, alcanza para dar testimonio de los diferentes procesos modernizadores, aniquiladores absolutos de las nociones de mimetismo y verosimilitud de las propuestas anteriores, aferradas al realismo y el representacionalismo estético ${ }^{1}$.

En este circuito de cambio y transformación surgen dos obras que, por su radicalismo, han venido concretando este cuadro fragmentario y multidisciplinar que caracteriza a las estéticas postvanguardistas de la literatura chilena. La Nueva Novela, publicada en 1977 y reeditada en versión facsimilar en 1985, y La Poesía Chilena, de 1978, constituyen la obra publicada en vida del poeta objetual y artista visual Juan Luis Martínez Hölger (1942-1993). En el universo poético que revelan estas dos composiciones artesanales, el lenguaje verbal se vuelve insuficiente hasta la invalidez y es complementado por múltiples lenguajes, como el iconográfico, el pictórico, el alfabestiario, el lenguaje de sordomudos, el lenguaje objetual y el nolenguaje o lenguaje truncado, propuestos mediante la ausencia de escritura de la página en blanco o la ausencia de significante de la página troquelada. Su nueva concepción y planteamiento de la realidad hace de estas obras paradigmas de un nuevo concepto del arte en el que todo parece descomponerse para mostrarse como mutable, etéreo y relativo, presentando, a través del fino hilo de la ironía, la desmitificación de buena parte de los anclajes establecidos por los grandes hitos históricos y culturales de Occidente.

\section{LA RUPTURA CON LA ESCRITURA PROGRAMADA: EL ANTI-PROGRAMA}

La estructura caleidoscópica de las dos obras que Juan Luis Martínez publicó en vida ha sido uno de los grandes retos de la crítica literaria de los últimos años. Tanto en La Nueva Novela como en La Poesía Chilena, se establecen complicadas relaciones

\footnotetext{
Al respecto pueden consultarse los estudios de Óscar Galindo (1999, 2000, 2004, 2005, 2006, 2007, 2009, 2010), donde el crítico trabaja los distintos procesos escriturales que conforman el panorama literario de Chile y buena parte del cono sur de América desde los inicios de la vanguardia hasta las últimas tendencias postvanguardistas.
} 
de intertextualidad que comprometen la propia teoría genettiana del palimpsesto, pues la combinatoria de los diferentes niveles de sentido comprometidos complejiza y aumenta las posibilidades expresivas e interpretativas de las mismas.

Entre los aspectos más destacados y menos trabajados por la crítica literaria se encuentra la inclusión de objetos tridimensionales al interior de las dos obras. Este gesto dota a sus trabajos de una noción multidisciplinar y multilingüística que los hace aparecer como innovadores y renovadores de un género corroído por el desgaste de la palabra, que por sí sola es incapaz de explicar el nuevo orden establecido en el arte. El lector, interpelado en múltiples ocasiones por el autor -escindido, "muerto" o remarcado a través de la tachadura del nombre y del pseudónimo-, se encuentra ante la radicalización absoluta del poema, llevado hasta su experimentación más compleja a través de la demostración de la existencia de variados y complejos lenguajes que operan en el arte.

La obra de Martínez, inscrita en un circuito literario de cambio y transformación radical, presenta un catálogo de distintos lenguajes que la hacen portadora de un extratexto que al mismo tiempo la sustenta, modifica la codificación binominal del lenguaje escrito a través de la ampliación del significante (Carrasco 1988) e incorpora nuevos elementos, distintos de la palabra, en la conformación de un símbolo corpóreo. De este modo, La Nueva Novela y La Poesía Chilena se convierten en iconos culturales y en modelos referenciales de una estética marcada por el rupturismo y la heterogeneidad. En ambas obras observamos un afán de pastiche que confirma, entre otras cosas, el estado de indefinición en que vive el arte en plena segunda mitad del siglo XX. Así, las mezclas de materiales puramente artísticos con otros que nunca habían pasado de su calidad de instrumentos cotidianos o la mixtura de géneros literarios y tipos discursivos, son evidentes signos de esta miscelánea disciplinaria y material. Tal experimentación textual y artística abre, anuncia e/o inaugura una tendencia dentro del panorama literario chileno a partir de 1977, la neovanguardia, que "asume los rasgos textuales de la vanguardia [...] y también los extratextuales" (Carrasco 1988: 37).

Aún cuando en Chile, junto con las poéticas experimentales de Huidobro y Parra, la obra de Martínez se instaura como innovadora y única, es necesario rastrear más allá de estas fronteras para encontrar otras afinidades de su trabajo. Artistas europeos como S. Mallarmè, con su poema espacial Coup de dés, M. Duchamp con su inodoro de porcelana firmado, los Caligramas de Apollinaire, las «palabras en libertad» de los futuristas, los collage dadá y los trabajos de movimientos como el letrismo o el concretismo, cuyos postulados de rechazo a lo natural, lo objetivo y lo simbólico, su preocupación por la expresión plástica o la superioridad de la forma sobre el color, dejaron huella en las vanguardias históricas a partir de los años '30; son algunos de los planteamientos con los que podemos relacionar la obra de Martínez. Pero, además, tal y como afirma Galindo:

Sus filiaciones filosóficas se encuentran en una delirante y humorística versión deconstructiva de las ciencias del lenguaje y de los paradigmas de la racionalidad. El nonsense es una de las claves literarias, el que lo vincula inevitablemente a Lewis Carroll en la tradición europea y a Vicente Huidobro en la hispanoamericana (Galindo 2000: 21).

Tales relaciones intertextuales con el nonsense nos remiten directamente a otro de los vínculos esenciales con los que se corresponde la obra de Martínez: Jean Tardieu. 
Desde su perspectiva antirrealista, antirrepresentacionalista y antiprogramática, Tardieu advierte la paradójica falta de correlación entre el "sentido" y el "sinsentido" proclamado por el nonsense, pues lo que realmente salvará a las artes creativas no es este último, sino un concepto final que, aglutinando el poder significante, pueda expresar La oscuridad del día (1974) y establecer la relación directa, como si de un eslabón perdido se tratara, entre los trabajos de los simbolistas franceses, el nonsense acuñado por Edward Lear y las vanguardias históricas:

Finalmente, obstinado en poder representar el poder expresivo de las artes creativas porque era esa mi intención esencial, como un dominio que escapaba, en su mayor parte, al dominio del lenguaje común- había llegado a imaginar el diálogo cara a cara del Sentido y del personaje proteiforme al que llamaba "Antisentido". Era, pensaba, el único término válido para responder a todas las sugerencias nacidas de una obra, las sugerencias innumerables, a menudo contradictorias que, iguales a los animales anfibios, pueden nacer y propagarse a la vez a varios elementos del espíritu, a varios niveles de existencia, sin perder esa unidad orgánica que los hace seres para siempre vivos... (Tardieu 2003: 984). ${ }^{2}$

La obra de Tardieu está íntimamente ligada al surrealismo bretoniano en sus inicios y va derivando, llegada su madurez, hacia una constante búsqueda de la expresión de todo lo que subyace al sentido. Para ello se hacía imprescindible un cambio en el modo de entender la realidad más como una experiencia sensorial que como una práctica definible. Lector asiduo de Mallarmé, Rimbaud, Verlaine y Baudelaire; pero también de Borges; marxista y amigo íntimo de Bretón, Éluard, Picabia y todo el círculo surrealista, Tardieu reflexiona en varias ocasiones en torno a lo que denomina "los sentidos de todos los sentidos" y plantea la existencia de un antisentido en las artes, necesario para llenar el vacío semántico en que queda el sinsentido:

Procuraba luego oponer "sentido" y "sinsentido", lo que no era nuevo: otros lo hicieron antes y mejor que yo.

Entonces pensé que aún me equivocaba y que chocaba con una imposibilidad lógica, como cuando Parménides consideró inadmisible la hipótesis: "ser no es y no ser es." Y sin embargo, el lenguaje tenido por objeto de Sentido no podía admitir el Sinsentido. O más bien, no admite el sinsentido cuando expresamos algo (Tardieu 2003: 983). ${ }^{3}$

Es así como Tardieu, intertexto incuestionable de la obra de Martínez, asocia todas las corrientes vanguardistas a un nuevo modo de representar lo real desde la

\footnotetext{
"Finalement, obstiné à me représenter le pouvoir expressif des arts créateurs -car c'était là mon propos essentielcomme un domaine échappant, pour sa plus grande part, à face le dialogue mouvant du langage commun -j'en étais venu à imaginer face à face le dialogue mouvant du Sens et d'un personnage protéiforme que $\mathrm{j}$ 'appelais: "Antisens". C'était, pensais-je, le seul terme qui fût assez mobile pour répondre à toutes les suggestions sigues d'une œuvre, suggestions innombrables, souvent contradictoires qui, pareilles aux animaux amphibies, peuvent naître et se propager à la fois dans plusieurs éléments de l'esprit, à plusieurs niveaux d'existence, sans perdre cette unité organique qui en fait des êtres à jamais vivants..."

"Je cherchais ensuite à opposer "sens" et "non-sens", ce qui n'était pas nouveau: d'autres l'ont fait avant et mieux que moi.

Alors j'ai pensé que je me fourvoyais encore et que je me heurtais à une impossibilité logique, comme lorsque Parménide juge irrecevable l'hypothèse: "Être n'est pas et non-être est." Et pourtant, le langage ayant pour but le Sens, ne pouvait admettre le Non-sens. Ou plutôt il n'y avait pas, il ne pouvait y avoir de non-sens lorsque nous exprimons quoi que ce soit".
} 
antirrepresentación y establece importantes vínculos entre su modelo escritural y el de Mallarmé, cuya obra Coup de dés (1897) suele considerarse el inicio de la tradición antirrepresentacionalista de la literatura occidental. Esta misma tradición se caracteriza porque las palabras recuperan su cualidad de formas, los blancos se vuelven activos y la diagramación de las páginas adquiere importancia a nivel semántico. A partir del Coup de dés se registra una reivindicación de la materialidad del signo que será continuada por las vanguardias y las postvanguardias. Esta situación, junto con la influencia de filósofos del lenguaje como Wittgenstein y también de las reflexiones de Roland Barthes, Michel Foucault, Jacques Derridá o Jean Baudrillard, lleva aparejada una revisión de la concepción metafísica de la manera en que el lenguaje se relaciona con el mundo; de la manera en que las palabras se relacionan con las cosas.

Desde la escritura que practica Martínez en sus obras, este antiprograma inaugurado por Mallarmé se materializa desde distintas estrategias como el uso del collage y las fotografías, diferentes tipologías textuales y, sobre todo, el uso reiterado de objetos tridimensionales, y da cuenta del anti-proyecto descrito por Tardieu en un constante ludus que, como ya anunciáramos, da cabida al extratexto y amplía el significante textual; un significante material que puede ser palpado, y que da como resultado una obra objetual de casi infinitas posibilidades interpretativas.

\section{El objetualismo martineano (o De Cómo palpar el lenguaje)}

Ante la crisis representacional que sufre el siglo XX el artista busca incansablemente el modo de expresar sus cuestionamientos, de dar forma a la realidad que percibe, de reconquistar el lenguaje; y en este afán surgen diferentes modos de experimentar con él, de expandirlo y llenarlo de múltiples y multiplicados sentidos. Es así como la pictografía, el collage y los objetos empiezan a llenar los espacios literarios y a conformar, dentro de la literatura, un nuevo tipo de obra-objeto significante y legible desde su corporeidad. Uno de los más logrados proyectos en este sentido es la obra de Juan Luis Martínez en Chile. Su apasionado juego con los espacios de la página, con las tipologías y tipografías lingüísticas, con las imágenes, los collage y los objetos dan como resultado dos obras de trascendente vanguardismo estético. En ellas aparecen algunos objetos que funcionan como textos legibles desde una complejidad variable y dependiente del -llamémoslo- horizonte de expectativas que posee el lector. Pero, además, estos signos o textos, en su cualidad objetual duplican la propia esencia del significante, pues como corpóreos que son, pueden ser vistos tanto desde su anverso -sentido- como desde su reverso -antisentido- y analizados según diferentes realidades subyacentes.

El objeto literario que incursiona en la obra de Martínez está dotado de una concepción artística que lo muestra, no como simple artefacto cotidiano, sino como elemento dotado de la noción de artificiosidad. Tal significación del término objeto lo diferencia de la materialidad representada por la cosa, puesto que el objeto alberga cualidades como lo "no natural" y lo "fabricado" aunque participa de nociones como ser "pasivo" e "independiente" que también posee la cosa (Moles et al. 1969). Por otra parte, cuando el objeto viola alguno de sus estratos de creación, se produce una transformación importante en su status como tal y adquiere una dimensión distinta de la que se le atribuyó en el momento de ser creado. Es en este instante cuando se traspasan las fronteras de un espacio semiótico -el que circunda al objeto en su 
dimensión funcional- a otro -el que se le atribuye como nuevo en el espacio en el que se introduce. Cuando el espacio semiótico nuevo en el que se inserta el objeto es el arte, este se mimetiza con la disciplina que lo alberga y toma los axiomas necesarios para funcionar y re-significarse dentro de la obra. En el caso de la literatura, este objeto-arte, que funciona como un texto de compleja significación, da lugar a una nueva técnica que llamaremos objetualismo y que se basa en la utilización de objetos en una obra poética como respuesta a los procesos de interdisciplinariedad, interculturalidad y mutación disciplinaria que se rastrean en la literatura para llenar los vacíos significantes que ya es incapaz de suplir el lenguaje verbal.

Todos los objetos son clasificables a partir del sistema que los contiene (Barthes 1985), por lo mismo, cada sistema tomará forma y significación a partir de los objetos que incluye. El sistema objetual que compone la obra poética de Juan Luis Martínez promueve un tipo de codificación extremadamente compleja donde los objetos, que poseen ya una significación y una función fuera del mismo, ven multiplicadas sus posibilidades significativas y funcionales, y operan dentro de la obra como textos interpretables en el contexto literario al que han sido adheridos. Esta significación extendida no está ligada en forma opuesta a la que le correspondía en su status primario como objetos separados de este corpus, sino que complementa tal status y amplía el signo-texto tanto en la concepción de su significante, que ahora puede ser visto desde diferentes planos de la realidad, como en la de su significado.

\section{Los Significantes PalPables en la obra de MartíneZ ${ }^{4}$}

Se pueden reconocer en La Nueva Novela y La Poesía Chilena, al menos, nueve objetos, de los cuales, seis pertenecen a la primera y cuatro a la segunda, siendo la banderita de papel volantín un objeto que opera en ambas obras. Los objetos que Martínez incorpora en ellas son: el caligrama chino, la página en blanco, el papel secante, la transparencia, los anzuelos, la fichas de lectura, los certificados de defunción, la bolsita de "Tierra del Valle Central de Chile" y las banderitas de papel volantín. Exceptuando la bolsita de "Tierra del Valle Central de Chile", todos estos objetos poseen una función específica fuera del sistema que venimos llamando "la obra poética de Juan Luis Martínez" y, por lo tanto, adquieren, en el momento de ser introducidas al nuevo sistema, morfemas añadidos que los disponen para funcionar dentro del mismo. No obstante, ante su entrada en el sistema no todos los objetos se comportan o reaccionan de la misma forma, pues algunos de ellos, a los que llamaremos "vulnerables", deben cambiar algún morfema de su significación global al entrar a formar parte de él. Sucede esto con el caligrama chino, las fichas de lectura, la página en blanco, el papel secante y la transparencia. Otros objetos, sin embargo, como los anzuelos, las banderitas de papel volantín, la bolsita de "Tierra del Valle Central" y lo certificados de defunción, mantienen, aún después de haber sido introducidos en este sistema, la marca de su propiedad objetual primaria. Estos serán lo objetos "no vulnerables" de la obra de Juan Luis Martínez.

El análisis que aquí se hace de los objetos contenidos en La Nueva Novela y La Poesía Chilena pretende connotar la función textual que éstos poseen dentro de las obras. Una explicación exhaustiva de sus posibles significaciones complejas necesitaría de otro tipo de estudio, pues las relaciones de intertextualidad comprometidas en el ejercicio literario que contemplan estas obras podría desbordar los límites exigidos y exigibles para un texto de estas características. 


\subsection{Los objetos “vulnerables” de la obra de Juan Luis Martínez}

El caligrama chino. Situado, sin paginar, entre las páginas 96 y 97 correspondientes al capítulo VI LA LITERATURA de La Nueva Novela, este objeto pone en evidencia uno de los grandes axiomas de la obra de Martínez referido a la realidad en relación con el lenguaje y su representación. La escritura china constituye para la mayor parte de Occidente un conjunto de grabados ininteligibles. En este caso, el signo está compuesto por un significante únicamente observable y palpable, pero no legible y un significado desconocido para lectores no familiarizados con la cultura china y su tipo de escritura; por lo tanto, desde el concepto del lenguaje que posee la cultura occidental, el signo está incompleto y, en consecuencia, la comunicación ha quedado truncada, puesto que hay interferencias que interrumpen la transmisión del mensaje y el intérprete es incapaz de decodificarlo. La misma condición de signo incompleto hace imposible la labor de rastrear la continuación del mismo dentro de la obra, a pesar de que la NOTA de la página 96, así como la página 97 (dedicada a "LA POESÍA CHINA"), reflexionan en torno a la existencia de la poesía china y a la correlación del taoísmo con la filosofía occidental.

Hay que tener en cuenta que en las culturas no occidentales como la china "los espacios visual y lingüístico permanecieron intrincados a lo largo de los siglos dado su propio sistema de escritura ideogramática" (Gache 2006: s/p). Así, la poesía china, poesía de lo visual, no podía ser creada por cualquier poeta, puesto que esta labor correspondía a alguien que aunara en sí las cualidades del poeta y del calígrafo. "Las palabras eran escritas para ser leídas en el espacio" (2006), al modo de los Caligramas de Huidobro, donde el factor visual complementa al plano de la escritura lineal.

Martínez halló en la escritura del chino la materialidad del lenguaje referida a su faceta más figurativa; y, en su gesto honorífico a la poesía china, dejó constancia de que, si bien es traducible, gran parte de la carga semántica de la misma se pierde en la traducción, pues en ella no se observan los elementos figurativos que la constituyen.

En cuanto a su condición de vulnerable, esta se manifiesta en el hecho de que, aunque el mensaje que transmite este caligrama queda incomprendido debido a nuestra incompetencia como lectores del chino, también es cierto que, perteneciendo éste a otro sistema, al introducirlo en la obra de Martínez, pierde gran parte de la carga semántica que le perteneció en el momento de ser creado. Si supiésemos leer el caligrama es probable que encontrásemos algún signo que lo asimilara a la obra de Martínez, pero este hecho no lo desvincularía del contexto en que se inscribió en un principio; y, además, seríamos capaces de reconocerlo. Sin embargo, al desconocer las variables necesarias para su decodificación, desconocemos también el significado metafórico que le correspondería a este objeto.

Las fichas de lectura. Introducidas en La Poesía Chilena como páginas de un libro, las fichas de lectura violan, desde este hecho mismo, el más importante de los estratos que le fueron concedidos en el momento de su creación. Las fichas de lectura son objetos independientes por esencia; al atraparlas en una compilación pierden gran parte de su status ontológico, puesto que una misma ficha de lectura puede servir en distintos contextos; funcionan como las piezas de un puzzle al modo de una sinécdoque del tipo "la parte por el todo"; dicho de otro modo, al compilarlas 
pierden su finalidad como tales. No obstante, en la compilación que se les haga en cada momento, adquirirán una significación de conjunto diferente. Dentro de $L a$ Poesía Chilena, las fichas de "Los sonetos de la muerte" de Gabriela Mistral, "Solo la muerte" de Pablo Neruda, "Poesía funeraria" de Pablo de Rokha y "Coronación de la muerte" de Huidobro, se erigen como cuatro relatos (poemas) fúnebres. Selladas por la Biblioteca Nacional indican, al igual que los certificados de defunción, su autenticidad y avalan así su lógica interna.

Al contrario que en el caligrama chino, en las fichas de lectura, significante y significado son perfectamente reconocidos por el lector. El significante es complejo, igual que en el caligrama; en él se pueden reconocer dos características destacables, el material de que está compuesto -que nos ayuda a definirlas como fichas y no como páginas- y la escritura. En cuanto a su posible traducibilidad o significado, estas fichas de lectura son las "señales de ruta" que el lector debe seguir para encontrar la estela que deja la muerte en la poesía chilena, ya que muertos están los poetas fichados y de muerte hablan los poemas referidos.

La página en blanco. Como objeto, la página en blanco (ubicada, sin numerar, entre las páginas 86 y 87 del capítulo VI LA LITERATURA en La Nueva Novela) constituye un significante simple e inmediatamente lleva al lector a pensar en la obra mallarmeana Coup de Dés. Como hemos visto en los casos del caligrama chino y de las fichas de lectura, los significantes complejos motivaban significados complejos, pero en la ausencia de escritura de la página en blanco está impresa la marca del silencio, la ausencia de lenguaje verbal. No obstante, como objeto, existe en toda su dimensión, puesto que podemos rastrear en ella las características de "no natural", "fabricado", "pasivo" e "independiente" que proponíamos como características del objeto. En ella, en la página en blanco como objeto, constatamos la afirmación referida a los dos elementos objetuales anteriores, puesto que, en definitiva, no se concreta la función para la cual se creó. En la blancura, la página, soporte de lenguaje verbal, ve frustrada la acción de significar respecto a un contenido, pero fortalece la significación que le corresponde como página virgen, definida en oposición a la no concreción de su funcionalidad.

En referencia a su vulnerabilidad, si arrancásemos la página en blanco de $L a$ Nueva Novela, ¿acaso no se convertiría ésta en una hoja de papel en blanco? Dejaría de ser "página" para pasar a ser "hoja"; perdería su status ontológico como parte de un complejo en espera de un significado que sí posee cuando está incluida en la obra.

El papel secante. El papel secante (correspondiente a las páginas 141 y 142) es un objeto doble. Como papel está referido en La Nueva Novela según la característica que le corresponde respecto de la función primaria para la que fue creado, la de absorber líquidos o exceso de tinta; pero como página, la característica primaria de absorbedor se doblega, puesto que sus dos lados cumplen la misma función en situaciones diferentes.

Si la pagina 142 (reverso del papel secante) ha absorbido la esencia compuesta en la página 143 y ha dejado en ella solo huellas que esperan una interpretación por reconocimiento de campo, no ocurre así con el "Portrait of a Lady" de la página 140, puesto que el papel secante no ha podido absorber en su totalidad las lágrimas vertidas de la mujer; escalofriante metáfora del desconsuelo, este objeto ve vulnerada su capacidad de actuación en la no-concreción del acto de "secar las lágrimas de la muchacha". 
La transparencia. En "Un problema transparente” podemos leer:

"Tardieu, ¿por qué si Usted se mira en un espejo a través de esta página, sólo puede observar cómo Usted mismo observa La Transparencia y no observa así también cómo La Transparencia es observada?" (Martínez 1985: 41).

Un poco más abajo encontramos La Transparencia y, a través de ella, leemos: "La Transparencia no podrá observarse a sí misma” (Martínez 1985: 41), frase que se encuentra en la página 43 y que leemos a través de la misma transparencia. La página 42 es exactamente igual a la 41, pero en La Transparencia se lee la frase de la página 40: "Si La Transparencia se observara a sí misma, ¿Qué observaría?" (Martínez 1985: 40).

Interpelado el lector en esta pregunta metafísica que relaciona el "yo" con el "otro" al plantear la posibilidad de observarse a uno mismo (Tardieu) o al otro (La Transparencia) sujeto y objeto se relacionan en un plano ontológico primario; de esencia y no de sustancia, porque la relación que se destaca en ellos compete a la posibilidad de la observación y no a la materialidad misma de la existencia. O sea, la pregunta a Jean Tardieu no está referida en el hecho de la existencia misma de La Transparencia o del mismo Jean Tardieu, sino en la posibilidad que tiene la transparencia para observarse a sí misma. Tal posibilidad está desligada de la materialidad del objeto por cuanto, siendo esta efectiva, en la idea de transparente está incluida la representación de la imposibilidad de vislumbramiento.

Esta transparencia, atrapada entre el troquel de una página y cuestionada en su propia esencia de transparente, pierde parte de su carga semántica, por cuanto, constituida como objeto material, es significante de la invisibilidad. Sin duda, hay alguna parte del significante que está truncada. En lo incoloro, en lo insustancial de su materialidad se nos plantea una cuasi imposibilidad de significar como objeto. Por otro lado, en su nombramiento, no como página transparente $u$ elemento transparente, sino como "transparencia", Martínez traslada el campo de significación primario de este objeto hasta el campo de significación que le corresponde, no como tal, sino como cualidad. La transparencia es lo transparente, cualidad de un objeto y, sin embargo, en La Nueva Novela, se constituye como elemento material nominado desde su propia esencia.

\subsection{Los objetos "no vulnerables” de la obra de Juan Luis Martínez}

Los anzuelos. Situados en el poema "Ictys" (pág. 73 de La Nueva Novela) encontramos, adheridos, dos anzuelos que lo coronan y lo cierran. Junto con la bolsita de "Tierra del Valle Central de Chile", este objeto es el único que no se establece como soporte de lenguaje verbal y cuyo material principal no es el papel. Además, no es portador en sí mismo de los axiomas necesarios para su significación, que debe ser completada en el conjunto del texto.

En la parte superior del poema, debajo del primer Quorum, podemos leer:

\section{(Cf. Nb. XVI,31, Is. V,14, Dt. XI,6, Ps. Cv. Dei. 17, Is. XXVI, 11)}

Excepto la referencia Ps. Cv. Dei. 17, el resto son pasajes del Antiguo Testamento; y se refieren, respectivamente, al Libro de los Números, Isaías y Deuteronomio. La alusión externa pertenece al Civitas Dei de Agustín de Hipona. 
Las claves de lectura de este objeto, invulnerables; puesto que al introducirlo en La Nueva Novela no pierde ninguno de los axiomas principales de que participa separado de esta. Pueden encontrarse en el paleocristianismo, periodo del cristianismo que va desde su origen, hacia el año 30, hasta el Concilio de Nicea, siglo IV. En esta época del Cristianismo, Jesucristo fue relacionado con la figura del pez; más concretamente con la de CETUS (ballena en griego). En griego, pez se dice IXTHUS. Con las letras iniciales de esta palabra los cristianos de los primeros siglos formaron un acróstico que rezaba Iésous Xhristos THeou Uios Soter (Jesucristo, de Dios el Hijo, Salvador). Entonces, ¿a dónde nos conducen las referencias bíblicas apuntadas? ¿Por qué representar la presencia cristiana con un anzuelo y no con un pez?

Todos estos pasajes bíblicos 5 , además de la referencia al Civitas Dei de Agustín de Hipona, hacen referencia a la furia desatada de Dios por la adoración de falsos dioses, destacando siempre la bondad y humildad de la divinidad. En ella queda anclada la humanidad, deudora de su enaltecido patriarcado y del deber de sumisión ante su presencia.

Resulta reveladora la relación que estos pasajes poseen con la figura autoritaria del dictador modelo que ha poblado buena parte de la historia del siglo XX en Occidente y que en La Nueva Novela aparece retratado en el "EPIGRAFE PARA UN LIBRO CONDENADO: LA POLÍTICA", donde pueden constatarse varias denuncias de los abusos de poder mediante diferentes estrategias discursivas, pictóricas y objetuales.

\footnotetext{
La primera referencia encontrada (Nb. XVI, 31 -en francés-) pertenece al Libro de los Números. El pasaje referido dice lo siguiente: $Y$ aconteció que, tan pronto como él hubo acabado de hablar todas estas palabras, el suelo que estaba debajo de ellos empezó a partirse. El segundo pasaje a que nos insta La Nueva Novela es el correspondiente al libro de Isaías capítulo V, versículo 14: Por lo tanto, el Seol, ha hecho espaciosa su alma y ha abierto ancha su boca, más allá del límite; y lo que en ella es espléndido, también su muchedumbre y su alboroto y el alborozado, ciertamente, bajará a él. ${ }^{\mathrm{h}}$. A primera vista, este pasaje no tiene ninguna relación con el anterior, pero si indagamos un poco más allá, encontramos que la referencia ${ }^{\mathrm{g}}$ ) nos lleva hasta Deuteronomio 28:63, donde dice: $Y$ tiene que suceder que tal como Yavé se alborozó sobre ustedes para hacerles bien y para multiplicarlos, jasí se alborozará Javé sobre ustedes para destruirlos y para aniquilarlos; ${ }^{k}$ y simplemente serán arrancados de sobre el suelo al cual vas a tomar posesión de él. Del mismo modo, la referencia $\left({ }^{\mathrm{h}}\right)$ nos lleva hasta Ezequiel 32:18, donde leemos: Hijo del hombre, laméntate sobre la muchedumbre de Egipto y hazla bajar, ${ }^{h}$ a ella y a las hijas de naciones majestuosas, a la tierra allá abajo, ${ }^{i}$ con los que van bajando al hoyo.. La tercera referencia pertenece al Deuteronomio; que es, como expresa su nombre, "la segunda Ley", una recapitulación, explicación y ampliación de la Ley de Moisés. La referencia que a nosotros nos compete es la correspondiente al capítulo XI, versículo 16; que dice: Cuídense por temor de que su corazón sea atraído seductoramente, ${ }^{m} y$ de veras se desvíen y adoren a otros dioses y se inclinen ante ellos, ${ }^{n}$. Al igual que en la referencia de Isaías, en esta, seguir los rastros de las notas nos lleva a otros dos pasajes que apuntan a una temática más punzante. El primero es Deuteronomio 4:34: ¿O intentó Dios venir para tomarse una nación de en medio de otra nación, con pruebas, ${ }^{k}$ con señales $^{l}$ y con milagros ${ }^{m}$ y con guerra ${ }^{n}$ y con mano fuerte $e^{o}$ con brazo extendido ${ }^{p}$ con gran aterramiento ${ }^{q}$ semejante a todo lo que Javé, el Dios de ustedes ha hecho por ustedes en Egipto delante de tus ojos? El segundo nos lleva hasta el Éxodo 14:23, y dice: Y los egipcios emprendieron la persecución, y todos los caballos de Faraón, sus carros de guerra y sus soldados de caballería empezaron a entrar tras ellosf, en medio del mar. Dejando para el final el dato que apunta hacia el Civitas Dei de Agustín de Hipona, veamos ahora hasta donde nos conduce la quinta y última referencia. Ésta es, de nuevo, de Isaías, capítulo XXVI, versículo 11, y leemos en ella: Oh Javé, tu mano ha llegado a estar elevada, [pero] ellos no [la] contemplan..$^{f}$ Contemplarán y se avegonzaráng ante el cielo por [tu] pueblo. Sí, el mismísimo fuego ${ }^{h}$ para tus propios adversarios se los comerá. Llegados a este punto, nos vemos obligados a salir de las Sagradas Escrituras y centrarnos en el Civitas Dei de San Agustín de Hipona. En Agustín se encuentra la doctrina sociológica de que el hombre es sociable por naturaleza ya que fue creado unum ac singulum. Esta individualidad lleva al hombre a agruparse de diferentes grados o formas de convivencia. En el término "civitas", él quiere denotar "la sociabilidad humana en cuanto dimensión del ser del hombre", pero no científicamente, sino en cuanto competencia intrínseca del mismo. En esta dimensión él distingue dos géneros de sociabilidad humana: la civitas Dei y la civitas terrena. Ambas no son objetividades entitativas sociales, sino diversas modalidades de funcionamiento social. Cabe destacar que ambas son definidas frente a tres propiedades trascendentales, notándose una gradualidad entre las mismas. Ellas son el bonum, la veritas y la charitas.
} 
De hecho, es propia de la neovanguardia una forma de escritura que simboliza la autocensura para poder decir a través de lo aparentemente inofensivo. Cabría indicar que La Nueva Novela, a través de estos pasajes, denuncia la muerte y la crueldad de muchos actos cometidos en nombre de una divinidad; o por la mano divinizada de aquellos falsos dioses que viven en la civitas terrena; convertidos en el Leviatán.

Los anzuelos del poema "Icthys", entonces, toman la forma simbólica de una atadura, de un poder del que es imposible soltarse y "el sublime pescador [...] Cristo de la mano rota, [...]" no logra atraparnos para salvarnos de la perdición última. Polisémicos en extremo, los anzuelos de La Nueva Novela aluden tanto al desmembramiento de casas de la portada de la obra como a la apertura de las aguas del Mar Rojo o al "¿cómo se representa usted la falta de pescado?” del intervenido Pequeños problemas y trabajos prácticos ${ }^{6}$ de Jean Tardieu, cuya respuesta más lógica, después de haber leído el poema "Icthys", sería: como una falta de fe.

Las banderitas de papel volantín. Como si intentara camuflarlo, una banderita patria de papel volantín cubre la portada del V capítulo de La Nueva Novela; "APÉNDICE PARA UN LIBRO CONDENADO: LA POLÍTICA”. Dentro de La Poesía Chilena, por cierto, está esperando ser cambiada por algún certificado de defunción.

Y ¿qué símbolo más político que una bandera? De hecho, recordemos lo que afirma Roberto Merino en su artículo "La constelación de los gemelos" cuando describe la atmósfera en que surge La Poesía Chilena:

La Poesía Chilena fue publicada en 1978, un momento de fuertes restricciones en la lectura política de todas las cosas. El campo de la lectura estaba, por decirlo así, minado, o bien sembrado de alarmas, como la patria misma. La presencia de la serie de banderas chilenas entre las páginas de este libro produjeron, si me acuerdo bien, algunas inquietudes en relación a la ambigua oscuridad del gesto. [...] La obra no es, sin embargo, solo signo de una época. Ha sobrevivido al paso de los años y al cambio de paisaje, y así la entendemos hoy. [...] Según toda evidencia, la estrella tonsurada en la cabeza de James King tiene una relación directa con la estrella solitaria de la bandera chilena. La estrella de la portada es en este caso fotográfica, hecha de luz fija, tal como las estrellas reales, pero fotográfica al fin (Merino 1998: 4).

Es inevitable, por la naturaleza invulnerable de este objeto, no pensar en la significación político-militar que posee. Pero además, esta banderita de papel volantín dieciochero constituye un objeto ampliamente significante por cuanto siendo soporte de lenguaje pictórico se erige como texto y ya no solo como signo al ser portadora de su propio significado invulnerable e histórico; carga de la cual no puede ser desposeída y que prevalece en cualquier contexto en que se encuentre. Su colocación en las páginas de La Nueva Novela ya apunta hacia un estado de cosas; la bandera no está situada en cualquier parte de la página, está colocada, metafóricamente, a media asta; lugar en que la bandera significa duelo, y donde, por lo tanto, quedan menguadas las significaciones paradigmáticas de "victoria y de autoafirmación" que se le atribuirían en estado puro.

\footnotetext{
Pequeños problemas y trabajos prácticos fue publicado por primera vez en el número 5 de la revista uruguaya Asir en 1948, traducido al español por W. Lockhart y con el subtítulo entre paréntesis "(Ejercicios de Fin de Curso)". Posteriormente Tardieu lo introduce en su obra Un mot pour autre (1951; Cf. 2003).
} 
La bandera es, junto con el himno nacional y el escudo, uno de los signos patrios de Chile. Como símbolo patrio, posee unas características invulnerables que hacen su aparición en el mismo momento en que se muestran a nuestros ojos. Pero esas características pueden, según qué momentos, ser ampliadas o resignificadas. De tal resignificación se ocupó Giovanna Yubinni en su artículo "La resignificación de los símbolos patrios en el contexto de la dictadura en Raúl Zurita y Elvira Hernández", donde la define del siguiente modo:

Un concepto cualquiera puede tener uno o más significados que han pasado por un proceso de incorporación que le ha otorgado la admisión en el sistema lingüístico de una comunidad, cuyos significados han sido consignados en diccionarios válidos para la lengua.

La resignificación, en cambio, es un proceso particular que no necesariamente tiene que ser aceptado por toda una comunidad lingüística, ya que es una nueva interrelación o lectura de un determinado concepto, propuesto desde disciplinas distintas $[\ldots]$

Parece ser que esto ocurre cuando surgen nuevas situaciones que producen tal inestabilidad que cuestionan la validez primaria de un concepto para un contexto específico; por lo cual, desde el ámbito del arte, surgen nuevas lecturas y proposiciones para comprenderlo (Yubinni s/f: 6).

La resignificación de La Bandera de Chile de Elvira Hernández constituye una representación no tradicional puesto que "su visión es que la bandera de Chile ha estado mucho tiempo sumergida en el ámbito de la cultura oficial -para el hablante ya extinta-, que es resguardada como reliquia en los museos, aquí símbolo de la burocracia" (Yubinni s/f:10). Así, efectivamente, unida al oficialismo de los certificados de defunción y las fichas de lectura, en La Poesía Chilena, la bandera simboliza ese oficialismo al que está sometida la tradición literaria y que se apropia, como sello y cuño, de la identidad de quienes bajo su ala han conformado el ámbito literario. Chilenidad y orgullo representa, oficialmente, la bandera, pero, cuando esta se expone a media asta, como en La Nueva Novela, el patriotismo se traduce en dolor, simula muerte y, por qué no, vergüenza por la calidad de esa muerte, que es además, una muerte colectiva representada por "La desaparición de una familia" que en su propia casa, símbolo de la patria también, no pudieron estar a salvo de la desgracia y "al fin" perdieron toda esperanza. A propósito de esto último, recordemos de nuevo, el título del capítulo que J. L. Martínez pre-anuncia dentro de La Nueva Novela reza "EPÍGRAFE PARA UN LIBRO CONDENADO: LA POLÍTICA" y está dedicado a Daniel Theresin, pseudónimo con que Jean Tardieu luchó y promovió el desplome del antisemitismo nazi desde el círculo surrealista.

La banderita chilena de papel volantín, soporte lingüístico, pero también único objeto doble en este sentido, portadora de lenguaje en tanto que significa, anuncia "La desaparición de una familia" y, al mismo tiempo, anuncia la condena a que quedará expuesto el libro que la contiene, así como advierte, en La Poesía Chilena, de la muerte de la poesía nacional. Desde este punto de vista podemos justificar su significación como texto, pues portador de múltiples significantes, proyecta una idea que se engarza con los múltiples significados simples que contiene. Así, la representación de patriotismo, de dolor por la muerte y de oficialismo, erigen un texto semiótico culto (Carrasco 1998) que ve re-significadas sus principales significaciones al constituirse en símbolo de denuncia de la muerte y desaparición de miles y miles de seres durante los periodos dictatoriales. 
La bolsita de "Tierra del Valle Central de Chile". El único objeto elaborado por Juan Luis Martínez, y que sólo tendrá significación dentro de este sistema es la bolsa de "Tierra del Valle Central de Chile". No obstante, este objeto está constituido por la unión de varios elementos; pero, al haber sido fabricado y en su calidad de no-natural (aunque la tierra que contiene es orgánica, en el uso que se le da cambia de categoría "cosa" a categoría "objeto") se concreta en un solo objeto.

Una bolsa de "Tierra del Valle Central de Chile" nunca va a significar otra cosa que no sea la de ser una bolsa que contiene tierra del Valle Central de Chile; pero, una bolsa de tierra del Valle Central de Chile introducida en una obra objeto que se titula La Poesía Chilena y que muestra, entre sus elementos, los certificados de defunción de los cinco grandes poetas de la tradición literaria chilena, adquiere, automáticamente, tintes de entierro. Y es que la tierra contenida en la bolsa plástica no es otra que la tierra del cementerio donde se encuentran los restos del padre de Juan Luis Martínez, aludido también en La poesía Chilena, como proveedor de los documentos que se muestran; y del que, como dato de fehaciencia, también se introduce el certificado de defunción. Retomamos de nuevo las palabras de Merino, referentes ahora a la bolsa de tierra, donde justifica la entrada del padre de Martínez en la obra como un gesto de patriotismo en su máxima expresión:

La tierra del Valle Central de Chile, incorporada a la obra -al fondo de la urna- es indesmentiblemente real. Se trata de la tierra patria donde se vuelven polvo los huesos de los padres. [...] donde los padres poéticos y el padre carnal yacen diseminados. En el mito y en la esfera real, la patria es el lugar al que invariablemente se intenta volver (Merino 1998: 4).

Los certificados de defunción. Un año antes de la publicación de La Poesía Chilena, Luis Guillermo Martínez Villablanca, padre de Juan Luis Martínez, muere en Viña del Mar. Junto a la copia facsimilar de su certificado de defunción, en un ataúd (objeto) de dimensiones 20 × 14,5 x 2,5 cms. su hijo encierra los de Gabriela Mistral (Lucila Godoy Alcayaga), Pablo Neruda (Neftalí Reyes Basoalto), Pablo de Rokha (Carlos Díaz Loyola) y Vicente Huidobro (Vicente García-Huidobro Fernández); acompañados de unas claves de lectura fichadas. Llama la atención en estos certificados "el perceptible uso del pseudónimo" (Merino 1998: 4) sobre los nombres reales.

Estos certificados de defunción, como objetos son soportes de lenguaje; en este caso, del lenguaje técnico-científico correspondiente a la medicina. Funcionan dentro de la obra bajo las mismas condiciones en que funcionarían en un registro civil dando fe de los datos del fallecido, las circunstancias que rodean su muerte (hora, lugar, fecha, etc.) y las causas de la misma.

Son invulnerables en el sentido de que mantienen su status primario como documento que da fe de la veracidad de un hecho, Martínez, sin embargo, consigue ampliar su significación hasta un espacio mayor; el de la poesía chilena, muerta en la muerte de sus grandes íconos poéticos. Fallecidos G. Mistral, P. Neruda, P. de Rokha y V. Huidobro; y enterrados, junto a sus poemas de muerte, el padre del poeta y el poema último que representa la bolsita de "Tierra del Valle Central de Chile", la tradición literaria chilena queda huérfana de madre. A la poesía chilena, enterrada en la cajita que la contiene, no le queda más que descansar por los siglos de los siglos 
en el recuerdo de la tradición para quedar viva en la memoria de los que la quisieron alguna vez. Así, La Poesía Chilena "siendo una restitución a la patria realizada en oscuros momentos, es también una restitución al padre. Iluminar la muerte del padre con la muerte de los poetas patrios corresponde a un acto del más alto valor afectivo, a un reconocimiento de pertenencia" (Merino 1998).

Como hemos visto, la reflexión en torno al lenguaje poético es una de las constantes que se pone de relieve en la obra poética de Juan Luis Martínez. Preocupado por los significantes, en un gesto de rebeldía con la palabra, amplía las posibilidades de esta dimensión del signo y la hace funcionar desde la presencia misma. El objeto es, entonces, en la obra de Martínez un signo no-verbal, por cuanto ha sido liberado de las ataduras de la fonética, que depende tanto de la significación que le asigne el intérprete como de la intención del autor.

\section{PARA CONCLUIR}

A lo largo del tiempo, los paradigmas artísticos han evolucionado acorde con las necesidades históricas que los rodean y, por lo tanto, definiciones, acciones y estrategias han sido ampliadas y modificadas con ellos. Desde fines del siglo XIX, en forma global, y, específicamente, hacia la década del 70, en Chile, todo el modelo literario occidental sufre un cambio radical; se funde con otros sistemas literarios y se difumina en sus límites para dar cabida a dispositivos heterogéneos que, siendo antes específicamente representantes de otras disciplinas o saberes, pasan a engrosar el inventario literario del siglo XX y se mantienen hasta la actualidad.

Uno de los máximos representantes de la mixtura que sufren las distintas disciplinas humanas -que no exclusivamente humanistas-, dentro del repertorio literario chileno de la década del 70 es Juan Luis Martínez. En las dos obras que publicó en vida se materializa la crisis de variados discursos que parecían imperar hasta mediados del siglo XIX en la literatura y que, con los simbolistas franceses sobre todo, explosiona en torno a una imperiosa necesidad: plantear la crisis de los discursos estables en el arte a partir de la formulación de un nuevo lenguaje que va más allá del verbo.

El objetualismo de Martínez actuó, dentro de la literatura chilena del periodo post-golpe, como un detonador, como un removedor de conciencias, y sentó las bases para la entrada en la escena artística de otros que revalorizaron el concepto de literatura; $y$, por consiguiente, de arte para funcionar fuera del formato libro en que se desgastaban las técnicas literarias.

De hecho, los objetos funcionan en la obra de Martínez con una lógica semiótica donde operan los mecanismos tradicionales que le son aplicables al signo y al texto. A partir de tal supuesto, hemos rastreado en este trabajo los siguientes objetos ampliados como signos en la escritura de este autor neovanguardista, cuya significación detallamos en el siguiente resumen:

Un caligrama chino cuyo significante, ampliado por la manera de su utilización fuera de una obra de arte china; y cuyo significado, desconocido por cualquier intérprete ajeno a la escritura oriental; genera una lógica semántica reconocible en su irreconocimiento: la interrupción del proceso comunicativo; unas fichas de lectura vulneradas en la manera en que son incorporadas a una compilación y despojadas de su posibilidad de actuar en cualquiera otra que ven cómo su significado adquiere una lógica de conjunto y se constituyen como el texto poético oficial que anuncia 
connotativamente la muerte de una tradición literaria: la chilena; un papel secante que al formar parte de la obra deja de operar como despojo del exceso de tinta y pasa a radicalizar su función primaria en un gesto de desconsuelo: la imposibilidad de absorber, del mismo modo que absorbe la tinta, las lágrimas vertidas por una muchacha que llora; una página en blanco que ve frustradas todas sus posibilidades de significar como continente de texto impreso y, sin embargo, pasa a significar como no continente de nada, en un gesto que la pone en contacto con el silencio; una transparencia que se convierte en objeto de sí misma y que en la presencia de lo transparente materializado concreta su característica de no-observable; puesto que, vista a través de un espejo, solo veremos lo que está detrás de ella; un anzuelo extraído del cajón de cualquier pescador que pasa a ser significante artístico y en cuyo significado hemos constatado la denuncia del horror provocado por los abusos de poder; una bandera chilena, significante textual-discursivo que trocó su significado positivo anclado al patriotismo en duelo por la muerte y la condena de los procesos artísticos, de la libertad de expresión y, en última instancia, del derecho a la vida; una bolsa de tierra del Valle Central de Chile cuyo significante complejo anuncia un significado afín; y, por último, unos certificados de defunción que, portadores de una verdad absoluta y oficial, constatan, como los textos de las fichas de lectura, la muerte de una tradición literaria que ha fallecido por distintas causas y que ha ido a fundirse con la tierra que algún día sostuvo su existencia.

Cada objeto es fuente recolectora de un tipo de discurso o modelo textual que opera al interior de los mismos y se activa como materializador y ampliador del signopalabra, dejando al descubierto una necesidad; no solo de denuncia por la desconfianza en esta misma palabra, sino de ampliación de los mecanismos de comunicación en el arte. Por otra parte, es pertinente señalar que, ninguno de los objetos de La Nueva Novela y La Poesía Chilena está despojado de la posibilidad de significar. En este gesto podemos sustentar nuestra idea de que los objetos complementan al lenguaje verbal y lo ayudan a operar dentro del arte, apropiándose de las ideas de mutabilidad del lenguaje y ampliación del repertorio literario.

De este modo y de acuerdo con lo planteado hasta aquí, hemos puesto de relieve en este trabajo los distintos tipos de discurso que se van abriendo camino entre las estancias de estas dos obras; el oficial político (que opera en la bandera), el oficial académico (materializado en las fichas de lectura de la Biblioteca Nacional), el oficial administrativo (dando cuenta del fallecimiento de cuatro poetas y un padre mediante sus respectivos certificados de defunción), el religioso (atado al anclaje de un anzuelo real y metaforizado a un tiempo), el ontológico (que plantea la posibilidad de observación de un elemento no visible -la transparencia- y, por lo tanto, hace dudar de su posible clasificación de existente como material), el pragmático (representado por un papel secante incapaz de secar lágrimas, pese a que éstas son tan líquidas como el exceso de tinta), el lingüístico (inoperante en la irrealización de sí mismo por cuanto ha dejado sin concreción el gesto de materializarse en una página), el poético iconográfico (que en un caligrama chino encuentra la representación pictórica a que tan poco acostumbrados estamos en Occidente) y, como no, el lenguaje de Martínez (que con una bolsa de tierra es capaz de demostrarnos que la vida no es lineal porque "polvo serás y en polvo te convertirás" como otra relación dialéctica más con La Biblia). 


\section{OBRAS CITADAS}

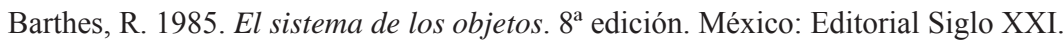

Carrasco, Iván. 1988. "Antipoesía y neovanguardia”. Estudios Filológicos 23: 35-53. 2002. "Interdisciplinariedad, interculturalidad y canon en la poesía chilena e hispanoamericana actual". Estudios Filológicos 37: 199-210.

Galindo, Óscar. 1999. "Poesía chilena de mediados de siglo. Tres poéticas de la vanguardia (Arteche, Lihn, Teillier)". Anales de Literatura Hispanoamericana 28: 589-610. . 2000. "El alfabestiario universal de La Nueva Novela de Juan Luis Martínez". Revista Chilena de Literatura 57: 21-40. . 2004. "Interdisciplinariedades en las poesías chilena e hispanoamericana actuales". Estudios Filológicos 39: 155-165. 2005. "Neomanierismo, minimalismo y neobarroco en la poesía chilena contemporánea". Estudios Filológicos 40: 79-94. .2006. "La tradición vanguardista en la poesía chilena de las últimas décadas". Crítica Hispánica XXVIII (1): 31-62.

. 2007. "Palabras e imágenes, objetos y acciones en la postvanguardia chilena". Estudios Filológicos 42: 109-121. .2009. "Neovanguardias en la poesía del cono sur: los 70 y sus alrededores". Estudios Filológicos 44: 67-80.

.2010. "El lugar de lo real: la poesía del cono sur en los años 60”. Estudios Filológicos 45: 23-33.

Ganche, Belén. 2006. "La poética visual: en las fronteras entre leer y ver. En

Lotman, Iuri. 1996. La Semiosfera I. Semiótica de la cultura y del texto. Edición de Desiderio Navarro. Madrid: Cátedra.

Martínez, Juan Luis. 1985. La Nueva Novela. Santiago de Chile: Ediciones Archivo. . 1978. La Poesía Chilena. Santiago de Chile: Ediciones Archivo.

Merino, Roberto. 1998. "La constelación de lo gemelos". En "Revista de Libros"de El Mercurio. Santiago (8 de agosto). Pág. 4.

Moles, A. et al. 1969. Los objetos. Argentina: Ed. Tiempo completo.

Tardieu, Jean. 2003. Euvres. Edición dirigida por Jean-Yves Debreuille. Francia: Gallimard.

Yubinni V., Giovanna. s/f. "La resignificación de los símbolos patrios en el contexto de la dictadura en Raúl Zurita y Elvira Hernández" (manuscrito). 